\title{
Cancer Peptide Vaccine S-588410
}

National Cancer Institute

\section{Source}

National Cancer Institute. Cancer Peptide Vaccine S-588410. NCI Thesaurus. Code C121776.

A cancer peptide vaccine containing five human leukocyte antigen (HLA)-A*2402restricted epitope peptides derived from as of yet not disclosed oncoantigens, with potential immunostimulating and antineoplastic activities. Upon administration of the cancer peptide vaccine S-588410, the peptides may stimulate a cytotoxic T-lymphocyte $(\mathrm{CTL})$ response against cancer cells expressing the antigens. This decreases proliferation of susceptible tumor cells. 